\title{
The evaluation of treatment plans in high-dose-rate endobronchial brachytherapy by utilizing $2 D$ and $3 D$ computed tomography imaging methods
}

\author{
Marcin Sawicki, MSc, Damian Kazalski, MD, Jarosław Łyczek, MD, PhD, Łukasz Kowalik, MSc \\ Brachytherapy Department, Subcarpathian Cancer Center, Brzozów, Poland
}

\begin{abstract}
Purpose: To present comparison of treatment plans made by using 2D and 3D methods in the planning system, as well as to assess the quality of treatment plans using the 2D and 3D methods.

Material and methods: The studies involved a group of 31 patients with advanced lung cancer treated in the Brachytherapy Department of the Subcarpathian Cancer Center in Brzozów from 2011 to 2013. In total, 31 patients and 76 treatment plans were analyzed. We compared coverage of PTV planned in 3D and 2D. In the 3D method of treatment, three-dimensional images from computer tomography were used. In treatment plans performed using the 2D method, images from the simulator were used.

Results: The comparison of treatment plans made by using 2D and 3D methods is described. This comparison highlighted the significant differences between these two methods assessing reference dose coverage of the PTV by $100 \%$ and $85 \%$ isodose.

Conclusions: Reference doses with 100\% coverage of the PTV in treatment applied with the 3D method are 31\% higher than when applied with the 2D method.

Key words: 3D planning, endobronchial brachytherapy, lung cancer.

\section{Purpose}

Lung cancer causes a therapeutic challenge in contemporary oncology. Current situation is the result of the increasing number of cases of patients being diagnosed in an extended state of the disease (ca $70 \%$ of cases - local extent) and its frequent occurrence in elderly people ( $\sim 50 \%$ above 65 years old, 30\% 70 years old), who are usually stressed with coexisting diseases. In these cases, there is no possibility of radical treatment - especially surgery. An important element of cancer treatment is palliative treatment, which mainly aims at improving the quality of life by mitigating the symptoms associated with the disease [1]. The endobronchial location of the cancer can cause hemoptysis, atelectasis, and many other related symptoms, such as dyspnoea, cough, and chronic inflammation. The removal of the endobronchial obstruction often significantly improves the health status of the patient, which in turn affects the quality of the patient's life. Highdose-rate (HDR) brachytherapy is one of the most effective methods used in palliative treatment [2-7].

In the application of treatment for endobronchial brachytherapy, the most commonly used orthogonal images are recorded using $\mathrm{X}$-rays, which provide good visualiza- tion of the catheter and the bone tissue. In cases where one catheter is used, in order to illustrate the distribution of the isodoses around the guide, the dose can be defined by the reference points. These points are located at a constant distance from the guide or can be designated at different distances from the catheter. If many guides are used, the dose in the area of the envelope is calculated. The envelope is the area containing the catheters, in which the dose is specified at the same depth. The aim of this method is to choose a calculation point located between all of the guides, as well as those farthest from the nearest guide. The selection of such a point allows for the inclusion of the minimal dose within the area of interest. During the treatment plans, the use of a larger number of guides and handling these guides with different reference points allows for the reduction or increase of the dose in the area of the tumor, simultaneously with the least possible coverage of critical organs $[8,9]$.

The paper present comparison of treatment plans made by using 2D and 3D methods in the Oncentra planning system 4.1 SP2 version, Brachy Planning Module (Nucletron, an Elekta company, Elekta AB, Stockholm, Sweden), as well as to assess the quality of treatment plans 
using the 2D and 3D methods. As such, the study is based on a group of patients treated in the Brachytherapy Department of the Subcarpathian Cancer Center in Brzozów.

\section{Material and methods}

The studies involved a group of 31 patients with advanced lung cancer treated in the Brachytherapy Department of the Subcarpathian Cancer Center in Brzozów from 2011 to 2013. In total, 31 patients and 76 treatment plans were analyzed.

Patients were treated with a microSelectron ${ }^{\circledR}$ unit (Nucletron, an Elekta company, Elekta AB, Stockholm, Sweden) with an ${ }^{192}$ Ir source, with a nominal activity of $10 \mathrm{Ci}$. The treatment was applied using the Oncentra Masterplan Brachy $4.0^{\circledR}$ system (Nucletron, an Elekta company, Elekta $A B$, Stockholm, Sweden). In brachytherapy, the Lumencath Applicator Set ${ }^{\circledR}$ was used (Nucletron, an Elekta company, Elekta AB, Stockholm, Sweden). All patient treatment was based on computed tomography of the thorax (CT GE Brightspeed, Milwaukee, WI, USA).

The endobronchial brachytherapy procedures were performed using local anesthesia under the control of a bronchovideoscope. During the bronchoscopy, guides were inserted in the bronchial tree and in the area of or near the tumor's location. In the 3D method of treatment, three-dimensional images from computer tomography were used, so the physician could contour the volume of the tumor and critical structures. The physicist reconstructed the catheter or catheters in the treatment plan system, activated the source position near the PTV area and then carried out the optimization of the treatment plan. In this method, graphic optimization was used most frequently.

In treatment plans performed using the 2D method, images from the Simulix Oldelft ${ }^{\circledR}$ simulator were used (Nucletron, an Elekta company, Elekta AB, Stockholm, Sweden). The dwell time was calculated in a different way: the catheter was created via virtual tomography, the length of the catheter, and the location of the source in it were the same as those in the 3D method, but the dose was specified to $1 \mathrm{~cm}$ from the catheter. The dwell time

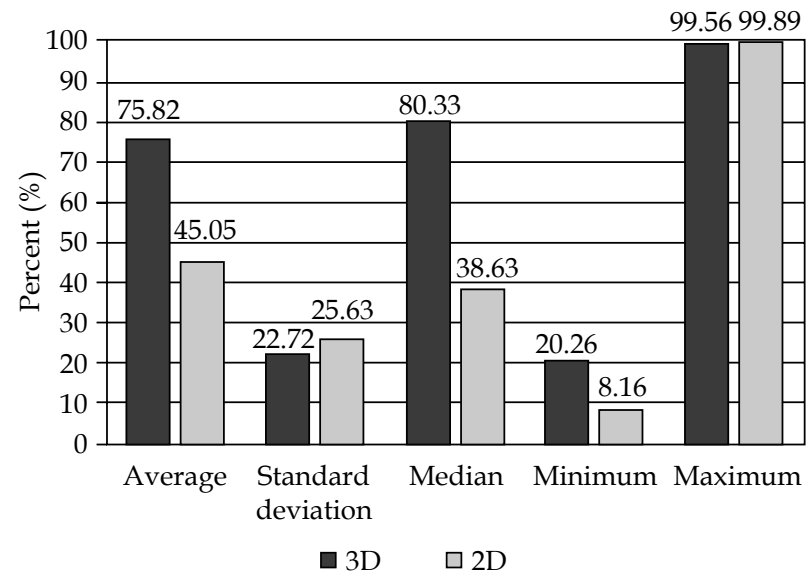

Fig. 1. Basic measures of outcomes: $\mathrm{PTV}_{100}$ in the 3D and the 2D methods calculated in the $2 \mathrm{D}$ method was transferred to the treatment plan performed based on the 3D imaging method. After changing the dwell time, a comparison was made of the reference dose coverage of the target (PTV) by the isodose of $100 \%$ and $85 \%$, and the calculation of the dose at $2 \mathrm{~cm}^{3}$ to the critical organ (spinal cord) was performer.

\section{Results}

Comparison of PTV coverage in the 3D method to the 2D method highlighted the significant differences between these two methods. Reference dose coverage of the target (PTV) by isodose of $100 \%$ and $85 \%$, as well as the dose to the critical organ received at $2 \mathrm{~cm}^{3}$ (in this case, the spinal cord), were compared.

\section{Dose coverage $100 \%$ PTV}

For the comparison of the variables in the $3 \mathrm{D}$ and the 2D methods, tests from two independent trials were used. The tests assumed unequal variances, which were most suitable for comparing quantitative variables in the two groups. In the case of $100 \%$ PTV, the $p$ value was 0.0001 , indicating that the statistical differences between the 3D and the 2D methods are significant.

Figure 1 depicts that the average method for the 3D and $2 \mathrm{D}$ was $75.82 \%$ and $45.05 \%$, respectively. The standard deviation for the 3D method was $22.72 \%$, and for the $2 \mathrm{D}$ method $-25.63 \%$, meaning there was a greater variation among the $2 \mathrm{D}$ results within the trial. However, the maximal values did not differ significantly between the 3D method and the 2D method (the maximal value in the $2 \mathrm{D}$ method was $0.33 \%$ higher than the maximal value in the 3D method). The reverse was observed for the minimal values; for the 3D method, the minimal value was $20.26 \%$, and for the 2D method it was $8.16 \%$.

\section{Dose coverage $85 \%$ PTV}

In cases where PTV was $85 \%$ (just as when PTV was $100 \%)$, the $p$ value was 0.0001 , which means that the statistical differences between the 3D method and the 2D method are significant. Figure 2 presents that the average

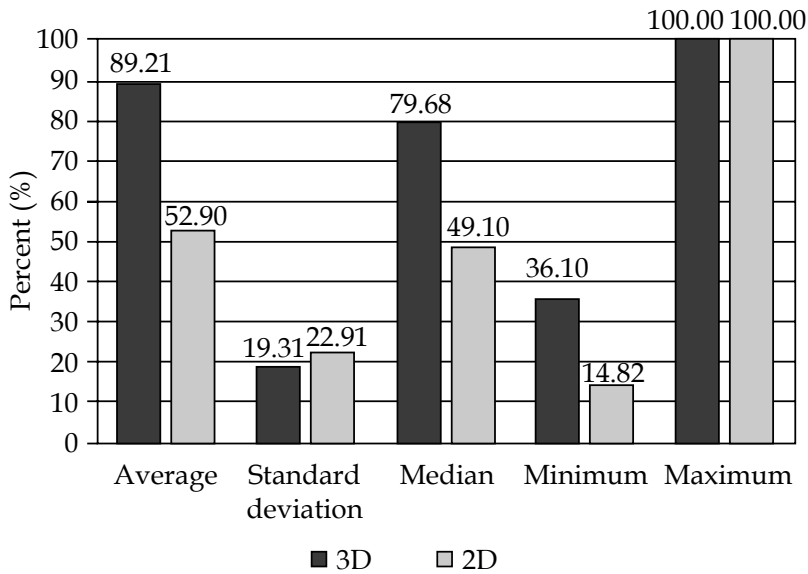

Fig. 2. Basic measures of outcomes: $\mathrm{PTV}_{85}$ in the $3 \mathrm{D}$ and 2D methods 


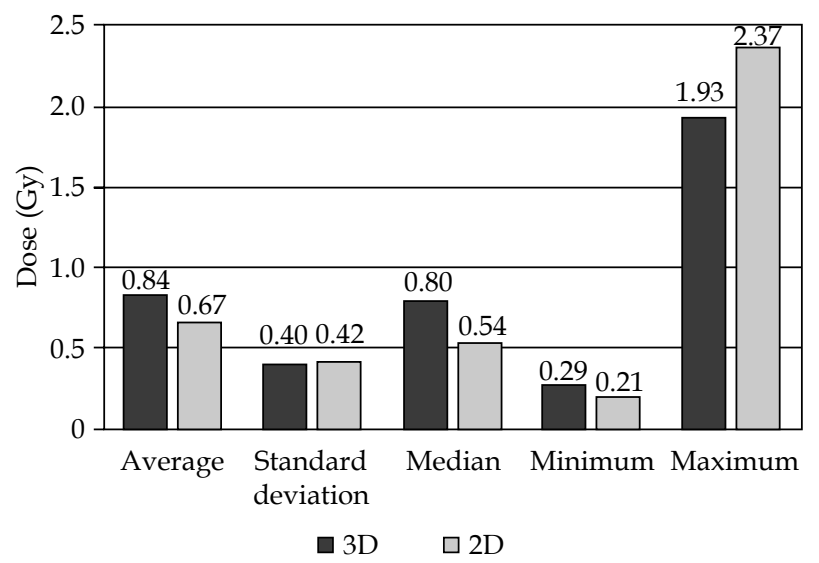

Fig. 3. Basic measures of outcomes: dose used on the spinal cord every $2 \mathrm{~cm}^{3}$ in the 3D and 2D methods

in the $3 \mathrm{D}$ method is $36.31 \%$ higher than in the $2 \mathrm{D}$ method, and the median in the 3D method is $30.58 \%$ higher than in the $2 \mathrm{D}$ method. The minimal value in the 3D method was $36.1 \%$ and in the 2D method it was $14.82 \%$. However, the maximal values did not differ significantly between the $3 \mathrm{D}$ and $2 \mathrm{D}$ methods.

\section{Dose for the spinal cord per every $2 \mathrm{~cm}^{3}$}

When the dose was used on the spinal cord every $2 \mathrm{~cm}^{3}$, the $p$ value was 0.009 , implying significant statistical differences between the 3D method and the 2D method. Figure 3 shows that the average value of the results for the 3D method are 0.17 Gy higher than in the 2D method. In the case of maximal values, the results for the 2D method are 0.44 Gy higher than for the 3D method. The standard deviation is not significantly higher (about $0.02 \mathrm{~Gy}$ ) for the 2D method than for the 3D method, when the dose was used on the spinal cord every $2 \mathrm{~cm}^{3}$.

\section{Discussion}

Complications that can occur after endobronchial brachytherapy such as hemorrhages, shunts, radiation-induced pneumonia or bronchitis and radiation-induced stenosis have justified the search for new and better solutions that can reduce these side effects $[10,11]$. The planning of treatment with the use of two-dimensional images cannot precisely determine where to find the area of the tumor. Specifying the dose of the points that are located at a distance of $1 \mathrm{~cm}$ from the applicator, we have no possibility to optimize the treatment plan while considering critical organs. With the 2D method, the dose to critical organs often exceeds the limit values and simultaneously disqualifies the treatment plan. In the 3D method, we can precisely determine the position of the tumor and critical organs, which allows us to optimize the treatment and limit the dose to critical organs.

Figure 4 provides a comparison between the DVH for both methods, where it can be seen that a much better coverage of PTV dose is required in the $3 \mathrm{D}$ method than

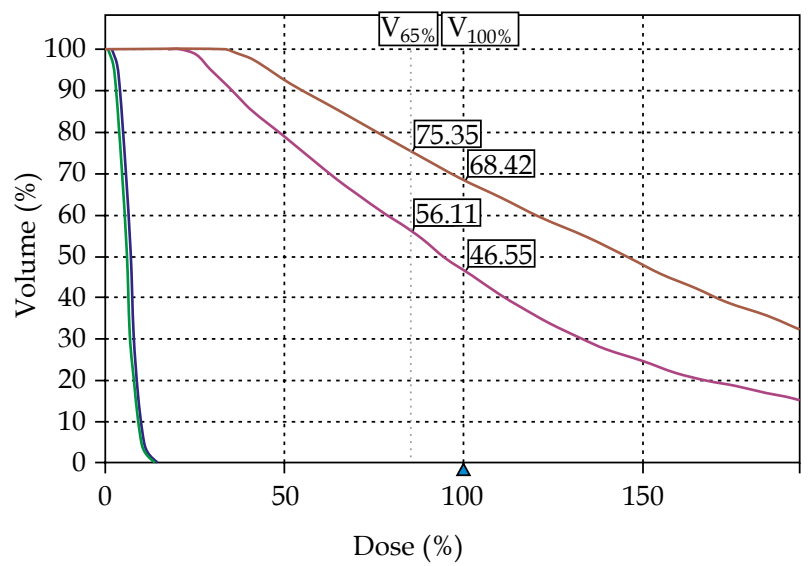

Fig. 4. Comparison of DVH for treatment plans in 3D (purple line) and 2D ( brown line) methods and the spinal cord (3D - green line, 2D - blue line)

the 2D. At the same time, we can notice that the dose the critical organs receive is slightly different in the two methods. We can clearly state that a plan using 3D images gives better results in terms of treatment planning. Technological progress and the utilization of computed tomography increases the possibility for treatment and reduces its toxicity. Applying treatment with the 3D method, the target area can be defined with high precision. For the 3D method, there is a possibility for dose optimization, decreasing the dose for the critical organs, and as a result, reducing the toxic effects of treatment on healthy tissue $[6,12,13]$. Computed tomography imaging is used in HDR in the treatment of bronchial carcinoma [14].

The main advantages of HDR brachytherapy include the simplicity of the procedure, short duration of treatment, and the possibility for patient to undergo the therapy in an outpatient setting [10]. Computed tomography allows for precise determination of the size of the tumor before the procedure, as well as determination of the changes in the bronchial tree that have occurred during therapy. In facilities that are CT-equipped, the 3D method should be routinely used in applying treatment in different localizations of tumors. The 3D method based on dynamic imaging should be a recommended technique in HDR brachytherapy.

\section{Conclusions}

The conclusions from the analysis and interpretation of the results of the research are as follows:

1. Reference doses with $100 \%$ coverage of the PTV in treatment applied with the 3D method are 31\% higher than when applied with the 2D method.

2. Determination of the target area and the area of critical tissues is possible to a far greater extent by the application of the $3 \mathrm{D}$ method than is the case with the $2 \mathrm{D}$ method. The former method allows for the administration of high therapeutic doses, while minimizing any impact on critical organs.

3. In the 2D method, application of dose is specified $1 \mathrm{~cm}$ from the catheter. When more than two catheters are 
used, "hot points" may occur. "Hot points" are those areas where the dose is much higher than specified. Such problems do not occur in the 3D method, which allows for uniformity of high doses.

\section{Disclosure}

Authors report no conflict of interest.

\section{References}

1. Kubaszewska M, Skowronek J, Młynarczyk W. Brachyterapia raka płuca w Wielkopolskim Centrum Onkologii. Sesja satelitarna. Przew Lek 2008; Suppl.: 17-19 [in Polish].

2. Skowronek J, Piotrowski T, Milecki P et al. Paliatywna brachyterapia HDR chorych na raka płuca leczonych w przeszłości z powodu innego nowotworu. Pol Arch Med Wewn 2003; CX, 1: 741-748 [in Polish].

3. Taulelle $M$, Chauvet B, Vincent $P$ et al. High dose rate endobronchial brachytherapy: results and complication in 189 patients. Eur Respir J1998; 11: 162-168.

4. Skowronek J, Adamska K, Zwierzchowski et al. Treatment of advanced lung cancer by external beam radiotherapy and high dose rate (HDR) brachytherapy. Rep Pract Oncol Radiother 2001; 6: 99-105.

5. Skowronek J, Kubaszewska M, Kanikowski M et al. HDR endobronchial brachytherapy (HDRBT) in the management of advanced lung cancer - comparison of two different dose schedules. Radiother Oncol 2009; 93: 436-440.

6. Łyczek J, Kazalski D, Kowalik $€$ et al. Comparison of the GTV coverage by PTV and isodose of $90 \%$ in 2D and 3D planning during endobronchial brachytherapy in the palliative treatment of patients with advanced lung cancer. Pilot study. J Contemp Brachytherapy 2012; 4: 113-115.

7. Golins SW, Ryder WD, Burt PA et al. Massive haemoptysis death and other morbidity associated with high dose rate intraluminal radiotherapy for carcinoma of the bronchus. Radiother Oncol 1996; 39: 105-116.

8. Makarewicz R, Fijuth J. Brachyterapia w leczeniu chorych na raka płuca. Wspolczesna Onkol 2002; 6: 39-44 [in Polish].

9. Mehta MP, Speiser BL, Macha HN. High dose rate brachytherapy for lung cancer. In: Nag S (ed.). High dose rate brachytherapy: a textbook. Futura Publishing Company, Armonk NY 1994; pp. 295-340.

10. Terlikiewicz J, Makarewicz R. Rola brachyterapii HDR w paliatywnym leczeniu pacjentów z zaawansowaną chorobą nowotworową. Pol Med Paliat 2006; 1: $64-69$ [in Polish].

11. Makarewicz R. Brachyterapia w raku płuca. Post Med Klin Dośw 1995; 4: $91-97$ [in Polish].

12. Skowronek J, Piotrowski T, Ramlau R et al. The repeated use of high dose rate brachytheraphy for locally recurrent lung cancer. Rep Pract Oncol Radiother 2003; 8: 127-137.

13. Kubaszewska M, Skowronek J, Chicheł A et al. The use of high dose rate endobronchial brachytherapy to palliate symptomatic recurrence of previously irriadiated lung cancer. Neoplasma 2008; 55: 239-244.

14. Tsai J, Cardarelli G, Corrao A et al. SU-FF-T-24: Comparison of Endobronchial HDR Brachytherapy Using CT Imaging and Conventional Simulator Filming. Med Phys 2005; 32: 1954 (abstract). 